\title{
Direct comparisons of the size and persistence of anisomycin-induced consolidation and reconsolidation deficits
}

\author{
James M. Stafford and K. Matthew Lattal ${ }^{1}$ \\ Department of Behavioral Neuroscience, Oregon Health and Science University, Portland, Oregon 97239-3098, USA
}

\begin{abstract}
An issue of increasing theoretical interest in the study of learning is to compare the processes that follow an initial learning experience (such as learning an association between a context and a shock; memory consolidation processes) with those that follow retrieval of that learning experience (such as exposure to the context in the absence of shock; memory reconsolidation and extinction processes). Much of what is known about these processes comes from separate experiments examining one process or the other; there have been few attempts to compare these processes directly in a single experiment. A challenge in between-experiment comparisons of consolidation and reconsolidation deficits is that they frequently involve comparisons between groups that are not matched on factors that may influence the size and persistence of these deficits (e.g., prior learning experience, memory expression prior to deficit). The following experiments examined the size and persistence of these deficits after matching both the amount of experience with a context and the levels of performance in that context prior to delivery of the protein synthesis inhibitor anisomycin. We found that systemic or intrahippocampal administration of anisomycin caused a deficit in groups receiving context conditioning (consolidation groups) or reactivation (reconsolidation groups) immediately prior to the injections. With systemic injections, the deficit was larger and more persistent in consolidation groups; with intrahippocampal injections, the initial deficit was statistically identical, yet was more persistent in the consolidation group. These experiments showed that when experiences and performance are matched prior to anisomycin injections, consolidation deficits are generally larger and more persistent compared to reconsolidation deficits.
\end{abstract}

There is substantial evidence in a variety of behavioral preparations that memories can be disrupted before they are completely formed, leading to the suggestion that memories are consolidated in a time-dependent manner (reviewed in McGaugh and Roozendaal 2009). When memories are reactivated they again may be subject to disruption, leading to the suggestion that memories must also be reconsolidated (reviewed in Alberini et al. 2006; Nader and Hardt 2009). Comparisons between effects of an amnesic manipulation, such as injections of the protein synthesis inhibitor anisomycin, after initial learning and memory retrieval have been instrumental in developing theories of memory consolidation and reconsolidation. However, most of what is known about the relation between hypothesized consolidation and reconsolidation processes comes from indirect comparisons of separate experiments examining one process or the other; there have been few attempts to compare these deficits directly in a single experiment. As a consequence, there are a number of very basic issues about the differences between consolidation and reconsolidation effectsincluding the relative size and the relative persistence of these effects-that remain unknown.

A challenge in using results from separate experiments to make general conclusions about consolidation and reconsolidation processes is that this necessarily involves comparisons between groups that are not matched on factors that may influence the behavioral effects. These factors, such as familiarity with the stimulus, the expression of behavior, and the internal state of the animal, both before and after the amnestic manipulation, all may influence the size and persistence of the deficits (e.g., Hinderliter

\footnotetext{
'Corresponding author.
}

E-mail lattalm@ohsu.edu; fax (503) 494-6877.

Article is online at http://www.learnmem.org/cgi/doi/10.1101//m.1452209. et al. 1975; Estes 1997; Biedenkapp and Rudy 2004). For example, in many preparations, manipulations designed to affect consolidation occur immediately after an animal's first experience with the behavioral treatment (e.g., contextual fear conditioning), whereas reconsolidation manipulations most frequently occur after the animal's second experience (e.g., re-exposure to the conditioning context). Thus, any effect on consolidation or reconsolidation is often confounded with the animal's previous overall history with the conditioned stimulus and with the different levels of behavioral response evoked prior to the deficit. This makes it difficult to determine whether group differences at behavioral and molecular levels are due to differences in specific memory processes or to other differences in experience or performance. By closely matching the experiences of different groups of animals, one can be more confident that behavioral and molecular differences reflect different memory processes (see Lee 2008, for a related approach).

An important issue that remains unresolved in comparisons between consolidation and reconsolidation is whether the behavioral deficit that is observed soon after treatment persists across longer retention intervals. The majority of studies examining consolidation deficits have found that these deficits persist across long retention intervals. Many studies also show persistent reconsolidation deficits, but many others show reversal of these deficits (reviewed in Amaral et al. 2008). Some attempts to account for these discrepancies suggest that reconsolidation deficits are sometimes smaller than are consolidation deficits, which may increase the likelihood that a reconsolidation deficit would reverse with time (e.g., Duvarci and Nader 2004). This is a reasonable hypothesis, but again, there have been few direct examinations of the differences in size and persistence of consolidation and reconsolidation deficits from common starting points in behavior. 
The purpose of the following experiments was to closely match the experiences of groups receiving amnestic treatment (systemic or intrahippocampal injections of the protein synthesis inhibitor anisomycin) following initial contextual fear conditioning and reactivation of the context-shock memory. This serves two purposes. First, by matching experiences and levels of behavior prior to the deficit, we can make direct comparisons between groups that received conditioning (consolidation groups) or reactivation (reconsolidation groups) immediately prior to anisomycin injections. Second, by matching the size of the anisomycininduced deficits in consolidation or reconsolidation, we can determine how the size of the original deficit is related to the amount of behavioral recovery after a long retention interval. If size of the deficit is a primary factor influencing recovery, then groups matched in size of initial deficit should show equal levels of recovery, regardless of whether the deficit reflects a consolidation or reconsolidation deficit.

\section{Materials and Methods}

\section{Subjects}

A total of 281 male C57BL/6 mice ranging in age from eight to 11 wk old were used in the experiments. All mice were either bred at Oregon Health and Science University (OHSU) or obtained from Jackson Laboratory (Bar Harbor, ME). The OHSU colony originated from C57BL/6J breeders periodically replaced with C57BL/6J mice acquired from Jackson Laboratory. Each polycarbonate cage housed four mice, which hung in a Thoren rack. Animals were allowed free access to lab chow and water during all experiments. Subjects were maintained on a 12-h light/dark cycle (lights on at $0600 \mathrm{~h}$ ). The laboratory temperature remained at $21^{\circ} \mathrm{C} \pm 1^{\circ} \mathrm{C}$. All experiments were performed during the animal's light cycle. Protocols were approved by the OHSU Institutional Animal Use and Care Committee and were conducted in accordance with National Institutes of Health (NIH) "Principles of Laboratory Animal Care."

\section{Cannulations and histology}

Isoflurane ( $2 \%-5 \%$ in air) was used to anesthetize mice throughout the cannulation procedure. After sedation, mice were mounted on a stereotactic apparatus designed for use in mice (Kopf). A small piece of the scalp was removed and the skull was then conditioned using Ketac conditioner (3 M ESPE), an abrasive that facilitates adherence of the glue to the skull. After $2 \mathrm{~min}$, the conditioner was rinsed off the skull using $1 \times$ phosphate buffered saline (PBS). Holes were drilled bilaterally above the hippocampus (AP-1.7 mm, $\mathrm{ML} \pm 1.5 \mathrm{~mm}$ ). Cannulae guides (Plastics One, Inc.) were then inserted into the holes and glued to the skull using Ketac dental cement (3 M ESPE). Before the surgery, stylets were inserted into each cannula to ensure that the cannulae holes did not get clogged. The injectors ( $28 \mathrm{ga}$ ) extended $0.5 \mathrm{~mm}$ below the cannula guide into the brain (2.0 mm total length). Forty-five minutes prior to surgery, mice were given Rimadyl (Pfizer) to manage postoperative pain. The entire cannulation surgery was performed under aseptic conditions and lasted $\sim 20 \mathrm{~min} / \mathrm{mouse}$. After the surgery, mice were individually housed.

After the behavioral experiments were completed, brains were removed and flash frozen in methyl butane chilled on dry ice for storage in a $-80^{\circ} \mathrm{C}$ freezer. Brains were later sectioned on a cryostat. Slices were stained using cresyl violet and evaluated to verify correct cannula track position (see Fig. 6 below).

Of the 107 mice cannulated, 68 were used in the final analysis. This was due to various factors, such as incorrect guide cannulae placement, guide cannulae coming loose, and health issues following surgery. Group sizes listed in the text include only mice with functional cannulae correctly placed in the hippocampus.

\section{Injections}

For systemic experiments, anisomycin (Sigma Aldrich) was dissolved in $10 \% \mathrm{w} / \mathrm{v} \beta$-cyclodextrin solution (Sigma Aldrich) for which $1 \times$ PBS was the solvent. This solution was used because $\beta$-cyclodextrin facilitates the water solubility of anisomycin, which is water insoluble at the concentrations needed for adequate dosing. Anisomycin or vehicle was administered subcutaneously (sc) at a dose of $75 \mathrm{mg}$ anisomycin/ $\mathrm{kg}$ mouse bodyweight ( $7.5 \mathrm{mg} / \mathrm{mL}$ solution) immediately and $2 \mathrm{~h}$ after the session to increase the duration of protein synthesis inhibition (Lattal and Abel 2004; Alberini 2008). Vehicle doses were an equivalent per kilogram dose of the $10 \% \mathrm{w} / \mathrm{v} \beta$-cyclodextrin PBS solution.

For the intrahippocampal experiments, anisomycin was diluted in PBS and then dissolved in $1 \mathrm{M} \mathrm{HCl}$. The $\mathrm{pH}$ was adjusted back to $\sim 7$ using $\mathrm{NaOH}$. PBS was added to reach the appropriate concentration for infusion (160 $\mu \mathrm{g}$ anisomycin/ $\mu \mathrm{L}$ PBS). The vehicle solution consisted of equal amounts of $\mathrm{HCl}$ and $\mathrm{NaOH}$ as in the anisomycin solution. Mice received bilateral intrahippocampal injections $(0.25 \mu \mathrm{L} /$ side $)$ of either anisomycin $(40 \mu \mathrm{g})$ or vehicle from a $5.0 \mu \mathrm{L}$ Hamilton syringe operated by a Harvard Apparatus Pump II Dual Syringe micropump. Injections were administered over $1 \mathrm{~min}$ at a rate of $0.25 \mu \mathrm{L} / \mathrm{min}$. Injectors were left in place for an additional $30 \mathrm{sec}$ to ensure diffusion of the solution into the brain. Each side was injected individually, one occurring immediately after the other. During the infusion animals were allowed to walk freely. Animals were only briefly restrained to remove the stylets and to insert/remove the injectors. The entire microinjection procedure took a total of $6 \mathrm{~min} / \mathrm{mouse}$.

\section{Apparatus}

\section{Fear conditioning}

A $21.5 \mathrm{~cm}$ diameter Plexiglas chamber measuring $23 \mathrm{~cm}$ in height was placed on a grid floor. The grid floor consisted of stainless steel rods $3.2 \mathrm{~mm}$ in diameter placed $0.5 \mathrm{~cm}$ apart (Coulbourn Instruments product $\mathrm{H} 10-35 \mathrm{M}-08)$. A $0.35 \mathrm{~mA}$ scrambled shock was delivered through the floor by a shock generator (Coulbourn Instruments product H24-61). An infrared activity monitor was fixed to the top of each chamber to record freezing (Coulbourn Instruments product H24-61). This context (CTX) was illuminated throughout the experimental session with the house light. The chamber was cleaned with water before each subject was placed in the CTX. The CTX apparatus was placed inside a sound attenuating chamber (Habitest Isolation Cubicle; Coulbourn Instruments product $\mathrm{H} 10-24)$. Infrared- and video-camera-based behavioral records were kept during all sessions.

There were four of these conditioned fear chambers in the experimental procedure room (down the hall from the mouse colony) which allowed all four animals in a group cage to be run simultaneously. Assignment to these chambers was counterbalanced across experimental groups.

\section{Behavioral procedures}

\section{General experimental design}

Each experiment consisted of habituation, reinforced and nonreinforced context exposures, and testing (described below). The goal of these experiments was to match the behavioral performance and CTX exposure before testing consolidation and reconsolidation groups for differences in the magnitude and persistence of their respective memory deficits. By also equating performance in the vehicle groups, we could directly compare the effects of anisomycin in the consolidation and reconsolidation groups. To accomplish this, the following general experimental design was used throughout all experiments in this manuscript (depicted in Fig. 1): On day 1 the reconsolidation group received the CTX 


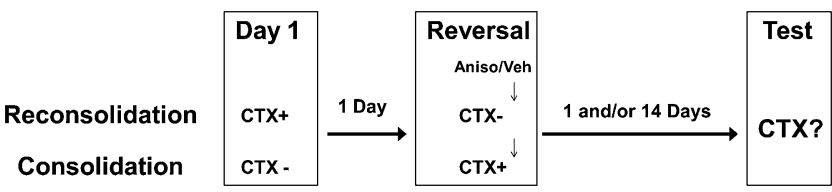

Figure 1. General experimental design. Mice in the reconsolidation group had context exposure reinforced with shock (CTX+) on day 1 and nonreinforced CTX exposure (CTX-) on day 2. The consolidation group had these contingencies reversed with nonreinforced CTX exposure on day 1 and reinforced CTX exposure on day 2. Consolidation and reconsolidation groups received anisomycin or vehicle treatment following the day 2 CTX exposure. Details about the CTX+, CTX-, and test treatments are provided in the text.

paired with shock $(\mathrm{CTX}+)$, while the consolidation group was exposed to the CTX in the absence of the shock (CTX-). On day 2 (reversal), the conditions were reversed such that the consolidation group received a CTX+ experience, while the reconsolidation group received a CTX- (no shock) experience. This reversal procedure ensured that all groups received the same amount of total context exposure and the same number of shocks. Immediately after the reversal session, mice were assigned to either anisomycin or vehicle groups. Group assignments assured that half the animals received anisomycin, while the other half received vehicle. Assignment into drug groups were based on levels of freezing behavior during reversal to ensure that both drug groups had reached a common level of performance prior to testing. Depending on the experiment, mice were tested on day 3 and/or day 17 by being placed in the CTX in the absence of shock (CTX-).

\section{Habituation}

All animals used in the systemic experiments were handled for $\sim 1 \mathrm{~min} / \mathrm{d}$ in the experimental procedure room for $3 \mathrm{~d}$ prior to the first conditioning CTX exposure. During handling, mice in the systemic experiments were given injections of $0.25 \mathrm{~mL}$ of $1 \times \mathrm{PBS}$ to habituate them to injections. Mice used in the cannulated experiment were given at least $3 \mathrm{~d}$ to recover from surgeries (e.g., Huang et al. 2007; Lattal et al. 2007; Vecsey et al. 2007). After recovery, mice were brought to the experimental room where they were handled and scruffed under environmental conditions similar to those present during drug infusion (e.g., microinfusion pump activated for background noise). The next day, mice were placed under light anesthesia and had their hippocampal stylets removed and dust caps attached to the guide cannula. Later that same day mice were again scruffed with light pressure being put on their cannulae to simulate the drug infusion experience. The following day experiments began.

Each day animals were brought into the experimental procedure room $1 \mathrm{~h}$ prior to the experimental session so they could acclimate to the ambient environment.

\section{Conditioning}

On the day of conditioning (CTX+) mice were placed into the context conditioning apparatus and received a 2 sec $0.35 \mathrm{~mA}$ footshock after 2.5, 5, 9, and $11.5 \mathrm{~min}$. Mice were removed $30 \mathrm{sec}$ after the final shock. This occurred on day 1 for the reconsolidation group and day 2 for the consolidation group. This CTX+ procedure was consistent throughout all of the following experiments.

\section{Experiment 1: Long nonreinforced exposure (systemic)}

The habituation, apparatus, general procedure, and systemic drug injection protocols used in this experiment were as described above. On CTX - days mice received a 12-min nonreinforced exposure. On day 1 the consolidation group received a 12-min
CTX - (no shock) exposure, while the reconsolidation group received a CTX+ experience. On the reversal day (day 2) the consolidation group received the CTX+ treatment, while the reconsolidation group received the CTX- treatment. The purpose of this reversal session was to bring the two groups to a common level of freezing immediately prior to the anisomycin treatment. Immediately after removal from the CTX, mice received a $75 \mathrm{mg} /$ $\mathrm{kg}$ sc dose of anisomycin or vehicle. They received a second identical dose $2 \mathrm{~h}$ after the reversal session. On day 3, animals were tested by placing them in the CTX in the absence of shock for $12 \mathrm{~min}$. There were 12 mice in all experimental subgroups except for the anisomycin consolidation group, which had 11.

\section{Experiment 2: Short nonreinforced exposure (systemic)}

Conditioning parameters used in this experiment were identical to those in experiment 1 . However, in this experiment the preexposure for the consolidation group and retrieval trial for the reconsolidation group were shortened to $3 \mathrm{~min}$, to minimize extinction during the retrieval trial. Systemic injection and testing procedures were identical to those used in experiment 1 . Mice in this experiment received a second, identical test $14 \mathrm{~d}$ later. There were 13 mice in each consolidation drug group, and 13 and 12 mice in the anisomycin- and vehicle-treated reconsolidation groups, respectively.

\section{Experiment 3: No pre-exposure (systemic)}

To determine whether context pre-exposure influences test performance in the conditioning groups, a group that did not receive pre-exposure was compared to a group that did receive preexposure. On day 1, this no pre-exposure group was briefly handled ( $\sim 10 \mathrm{sec} /$ mouse) and placed back in their home cage. The pre-exposure group received a 3 min nonreinforced context (CTX-) exposure on day 1 , as in experiment 2 . On day 2 , both groups received the context-shock pairings (CTX+) and systemic anisomycin or vehicle injections as described above. Testing procedures were identical to those used in experiments $1-3$. There were 10 mice in the anisomycin- and nine mice in the vehicletreated pre-exposure group. In the no pre-exposure group there were nine anisomycin-treated mice and 11 vehicle-treated mice.

\section{Experiment 4: No retrieval (systemic)}

To investigate whether anisomycin-induced deficits in the reconsolidation group were dependent on memory retrieval or some nonspecific action of anisomycin, a group that did not receive the memory retrieval trial was used. This no-retrieval group received the same CTX+ experience on day 1 as the retrieval group. However, on day 2 when the retrieval group received a 3 min nonreinforced context exposure, the no-retrieval group was handled for $\sim 10 \mathrm{sec}$. Immediately and $2 \mathrm{~h}$ after their respective day 2 experiences mice in both groups received either anisomycin or vehicle injections as described in experiment 1 . Mice in the vehicle and anisomycin no-retrieval groups were matched based on their average freezing levels during day 1 conditioning. Testing parameters were identical to those used in experiments $1-4$. There were nine mice in all subgroups except in the no-retrieval vehicletreated mice, which contained eight.

Experiment 5a: Short nonreinforced exposure (intrahippocampal) with 1- and 14-d tests All context exposure and conditioning procedures were identical to those used in experiment 2 (3-min nonreinforced exposure). Immediately after day 2 (reversal) mice received bilateral infusions of either anisomycin or vehicle into the hippocampus. Mice were tested the next day and $14 \mathrm{~d}$ later, as in experiment 2 . There were nine mice in the anisomycin-treated and eight mice in the vehicletreated consolidation group. In the reconsolidation group there 
were eight anisomycin-treated mice and nine vehicle-treated mice.

\section{Experiment 5b: Short nonreinforced exposure (intrahippocampal) with only 14-d test}

To ensure that the first test (day 3 ) did not influence behavior during the second test (day 17), a group that did not receive the first test was used. The group that received test 1 (experiment 5a) and the group that did not receive test 1 (experiment $5 b$ ) received identical conditioning, reversal, intrahippocampal injections, and test 2 procedures as were used in experiment 2 . There were eight mice in each of the consolidation drug subgroups and nine mice in each of the reconsolidation drug subgroups.
A

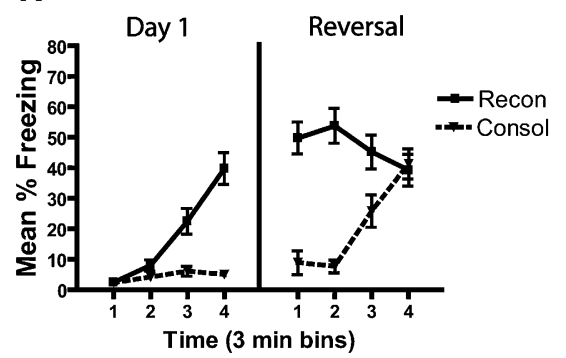

B

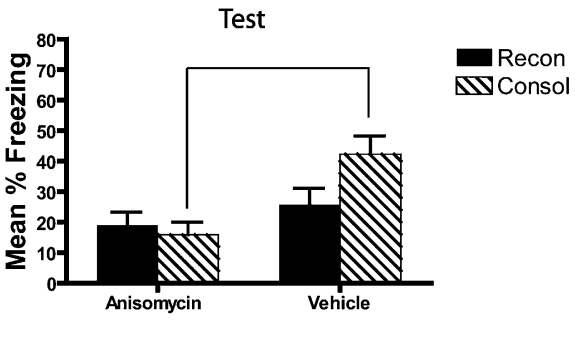

Figure 2. Post-acquisition anisomycin treatment blocks memory expression, while anisomycin treatment following a $12 \mathrm{~min}$ retrieval trial does not affect performance when tested $1 \mathrm{~d}$ later. $(A)$ During reversal, mice in the consolidation (CTX+ exposure) and reconsolidation (CTX - exposure) groups were brought to the same level of behavioral performance immediately prior to anisomycin and vehicle treatment. $(B)$ During a test the next day, the anisomycin-treated consolidation group showed impaired fear memory expression relative to their vehicle treated controls. Anisomycin did not change the reconsolidation group's freezing behavior relative to controls, likely due to extinction in the reconsolidation vehicle group.

\section{Data analysis}

\section{Behavior}

In all experiments, fear memory expression was evaluated by measuring freezing behavior. Freezing behavior in the systemic experiments was defined as the absence of detected movement for at least 3 sec using the Coulbourn infrared activity monitors (e.g., Boatman and Kim 2006; Lattal 2007a). In the intrahippocampal experiments, freezing (absence of all movement except respiration) was assessed every $8 \mathrm{sec}$ by a trained observer who was unaware of group assignments.

\section{Recovery testing}

Spontaneous recovery is sometimes assessed by examining changes in performance from the first test to the second test. These between-test comparisons are difficult, especially with long test intervals due to the varied and sometimes uncertain influence of time on behavioral performance. As such, our analyses of recovery focus on common test session comparisons between groups, so that any potential nonspecific time-dependent influences on performance will be controlled across all groups (e.g., Rescorla 2004).

\section{Statistics}

Analyses of variance (ANOVAs) were used to evaluate fear acquisition and extinction. Greenhouse-Geisser corrections were used to account for violations of the sphericity assumption in withinsubjects measures. ANOVAs were used to evaluate differences during days 1 and 2, as well as during the test sessions. During days 1 and 2, effects of context treatment order (unshocked on day 1 , shocked on day 2 in consolidation groups; shocked on day 1 , unshocked on day 2 in reconsolidation groups) and 3-min time block were factors. Test differences were evaluated by examining effects of context treatment just prior to injections (corresponding to consolidation or reconsolidation groups) and drug (anisomycin or vehicle). All a priori hypotheses (e.g., anisomycin and vehicle comparisons within consolidation and reconsolidation groups) were tested with two-tailed Student's $t$-tests; $\alpha$ levels for all comparisons were held at 0.05 .

\section{Results}

Experiment 1: Long nonreinforced exposure (systemic) In this experiment we used a 12 min nonreinforced context exposure (CTX-) and a 12 min reinforced exposure (CTX+). As can be seen in Figure 2, during day 1, the reconsolidation group increased freezing throughout the reinforced session (CTX+) and the consolidation group showed low levels of freezing throughout the nonreinforced pre-exposure session (CTX-), which was confirmed by a reliable two-way interaction between time block and context treatment (reinforced or nonreinforced; $F_{(1.6,67.9)}=$ 33.2, $P<0.001)$. The increase in freezing during the CTX+ treatment was reliable in the reconsolidation group $\left(F_{(1.4,32.5)}=\right.$ 44.8, $P=0.001$ ).

During day 2 (reversal), mice in the reconsolidation group showed some loss of freezing during the nonreinforced context treatment (CTX-), but the consolidation group increased freezing over the course of the reinforced context treatment (CTX+). This was confirmed by a reliable interaction between time block and context treatment during day $2\left(F_{(1.6,67.9)}=33.2, P<0.001\right)$. This interaction was driven by a decrease in freezing throughout the CTX - session in the reconsolidation group $\left(F_{(2.5,58.3)}=9.8, P<\right.$ 0.001 ) and a concurrent increase in freezing throughout the 12 min CTX+ session in the consolidation group $\left(F_{(2.1,45.9)}=23.3, P<\right.$ $0.001)$. Freezing levels between the consolidation and reconsolidation groups were statistically equated during the final 3-min block of the day 2 session $\left(t_{(45)}=0.28, P=0.78\right)$. There were no interactions or main effect of post-reversal drug treatment group during days 1 or 2 (all $P>0.05$ ). These results show that the reversal session was successful at bringing the reconsolidation and consolidation groups to a common level of performance prior to drug treatment and subsequent memory testing.

During the test (Fig. 2B), the two anisomycin-treated groups showed similar levels of freezing. Only the consolidation group appeared to show a memory deficit relative to its vehicle control. However, the reconsolidation vehicle group showed very low levels of freezing; thus, extinction in that group may have masked any anisomycin-induced reconsolidation deficit. There was a reliable main effect of drug group during the test, with the anisomycin groups showing less freezing behavior overall compared to the vehicle groups $\left(F_{(1,43)}=10.96, P=0.002\right)$. The anisomycin-treated mice froze less than did the vehicle-treated mice in the consolidation group $\left(t_{(21)}=3.6, P=0.002\right)$, but there was no simple effect of drug within the reconsolidation group. This indicates that while the 12 min nonreinforced exposure on reversal was successful in matching freezing in the reconsolidation and consolidation groups, the retrieval trial also resulted in significant extinction, which may have masked any reconsolidation deficit that might have existed. Thus, in the next experiments, the retrieval trial was shortened in an attempt to prevent significant extinction in the vehicle-treated reconsolidation group. 


\section{Experiment 2: Short nonreinforced exposure (systemic)}

To engage memory reactivation while minimizing behavioral extinction, the day 2 CTX - retrieval trial was shortened to $3 \mathrm{~min}$. To equate the nonreinforced context experiences in the consolidation group, their day 1 CTX - pre-exposure also was shortened to 3 min. Figure $3 \mathrm{~A}$ shows that these treatments resulted in fear acquisition throughout the day 1 session in the reconsolidation group (main effect of time block; $F_{(1.5,35.1)}=95.3, P<0.001$ ) with little freezing in the pre-exposed consolidation group. During reversal (day 2) freezing in the consolidation group increased throughout the CTX+ session $\left(F_{(1.9,45.5)}=1.5, P<0.001\right)$ to the same level of performance during the 3-min CTX- memory retrieval session in the reconsolidation group (no difference between the last 3-min block of freezing in the consolidation group relative to the reconsolidation group's 3-min retrieval session; $P>$ 0.05 ). On both days 1 and 2 , the mice to be treated with anisomycin or vehicle did not differ in freezing levels within each context treatment (all $P>0.05$ ). This procedure was therefore successful in matching the asymptotic behavioral performance, context exposure, and shock exposure of the reconsolidation and consolidation groups prior to amnesic treatment and testing.

During the 1-d test (Fig. 3B) freezing was lower in the anisomycin-treated mice compared to vehicle-treated mice in both the consolidation and reconsolidation groups. This deficit appeared larger in the consolidation group compared to the reconsolidation group. A significant overall effect of drug group indicated that anisomycin-treated animals froze less than did the vehicle-treated animals during the 1 -d test $\left(F_{(1,47)}=39.2, P<\right.$ 0.002). Further analysis of this effect revealed that the anisomycintreated mice froze less than did vehicle-treated mice in both the consolidation $\left(t_{(24)}=4.9, P<0.001\right)$ and reconsolidation groups $\left(t_{(23)}=3.9, P=0.001\right)$. There was no reliable interaction between drug and context treatment $\left(F_{(1,47)}=1.6, P=0.21\right)$, but although the vehicle-treated mice did not differ, the anisomycin-treated reconsolidation group froze significantly more than did the anisomycin-treated consolidation group $\left(t_{(24)}=2.5, P=0.02\right)$. Together, these results indicate that the consolidation deficit was larger than was the reconsolidation deficit during the 1-d test.

During the 14-d test (Fig. 3C), freezing was lower in the anisomycin-treated mice compared to vehicle-treated mice in the consolidation group, but not in the reconsolidation group. There was a reliable main effect of drug $\left(F_{(1,47)}=18.7, P<0.001\right)$ and context treatment $\left(F_{(1,47)}=15.0, P<0.001\right)$ during the 14 -d test, with no reliable interaction $\left(F_{(1,47)}=3.4, P=0.07\right)$. The anisomycinand vehicle-treated mice in the reconsolidation group did not differ $(P=0.1)$, but the anisomycin-treated consolidation group continued to show less freezing than their vehicle controls $\left(t_{(24)}=\right.$
$4.5, P<0.001)$. The 14 -d test therefore suggests that the consolidation deficit persisted to $14 \mathrm{~d}$, but the reconsolidation deficit did not.

\section{Experiment 3: No pre-exposure (systemic)}

It is possible that the CTX pre-exposure in the consolidation group could influence subsequent test behavior and the memory deficits seen in experiments 1 and 2 . To investigate this, a group that did not have context pre-exposure (no pre-exposure group) was compared to a group that did have the CTX pre-exposure on day 1 (pre-exposure group). A freezing deficit was observed in both preexposed and non-pre-exposed anisomycin-treated mice (Fig. 4). These deficits were equal in size in both the pre-exposed and nonpre-exposed groups confirmed by a main effect of drug $\left(F_{(1,33)}=38\right.$, $P<0.001)$ and no significant interactions or effects of subgroups (all $F<1$, all $P>0.7$ ). Thus, a 3-min pre-exposure to the context on day 1 did not alter the anisomycin-induced consolidation impairment.

\section{Experiment 4: No retrieval (systemic)}

To evaluate whether the reconsolidation deficit observed in experiment 2 (Fig. 3) was actually due to disruption in memory processes during retrieval and not some nonspecific action of anisomycin, the effects of anisomycin were compared in groups that did or did not receive the retrieval trial on day 2 . Visual inspection of Figure 5 suggests that the animals who received anisomycin after retrieval showed a significant freezing impairment when tested $1 \mathrm{~d}$ later. In contrast, the group that received anisomycin treatment without memory reactivation showed no deficit. A main effect of $\operatorname{drug}\left(F_{(1,33)}=7.5, P=0.01\right)$ in the absence of a significant context treatment $\times$ drug interaction $\left(F_{(1,33)}=1.5\right.$, $P=0.24$ ) confirmed that there was less freezing in the anisomycintreated animals compared to controls. This drug effect was due to the freezing deficit in the retrieval group $\left(t_{(17)}=2.7, P=0.014\right)$ as the no-retrieval group showed no such deficits $(P=0.29)$.

\section{Experiment 5a: Short nonreinforced exposure (intrahippocampal) with 1-d and 14-d tests}

Figure 6 shows injector tip placement for all mice and a representative brain slice from a cannulated mouse. Mice that received conditioning on day 1 (reconsolidation groups) increased freezing over the course of the session $\left(F_{(3,68.9)}=83.5, P<0.001\right)$, whereas mice that received pre-exposure showed very low levels of freezing (Fig. 7A). On day 2 (reversal), the consolidation groups increased freezing during the course of the session $\left(F_{(3,56.2)}=91, P<0.001\right)$. Freezing during the last $3 \mathrm{~min}$ of the conditioning session in the consolidation group was not statistically different from freezing
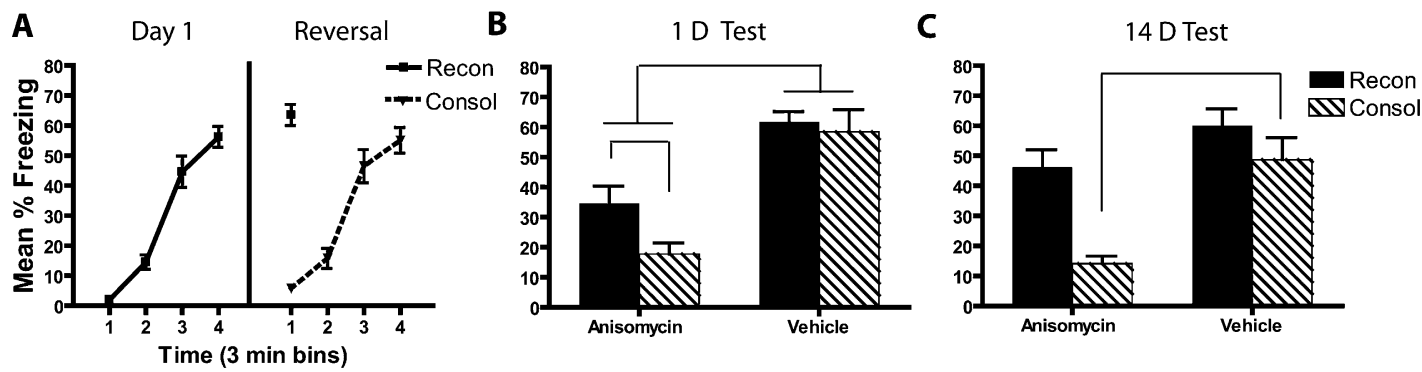

Figure 3. Systemic anisomycin-induced consolidation deficits are initially larger in magnitude and more persistent (to at least $14 \mathrm{~d}$ ) compared to reconsolidation deficits. $(A)$ During the last 3 min of the reversal fear conditioning session (CTX+), the consolidation group showed similar levels of freezing to the 3-min retrieval session in the reconsolidation group. Immediately and $2 \mathrm{~h}$ after this reversal day mice received either anisomycin or vehicle treatment. $(B)$ When tested $1 \mathrm{~d}$ later, the vehicle-treated mice from the reconsolidation and consolidation groups showed equivalent levels of freezing. Mice treated with anisomycin after initial memory acquisition or retrieval showed freezing deficits compared to their vehicle controls. This deficit was larger in those mice treated after retrieval than it was in the mice treated after acquisition. (C) The anisomycin-induced deficit only persisted in the consolidation group; freezing recovered to vehicle levels in the reconsolidation group during the 14-d test. 


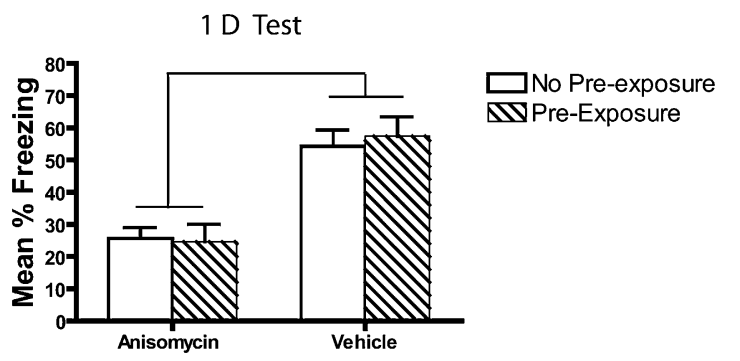

Figure 4. CTX pre-exposure does not influence the magnitude of an anisomycin-induced freezing deficit when tested $1 \mathrm{~d}$ later. Mice received either 3-min CTX exposure (pre-exposure) or handling (no pre-exposure) $1 \mathrm{~d}$ prior to a 12 -min fear conditioning session. Immediately and $2 \mathrm{~h}$ after the conditioning session mice were injected with either anisomycin or vehicle. Testing $1 \mathrm{~d}$ later shows an anisomycin-induced freezing deficit that was equal in magnitude between the pre-exposure and no preexposure groups.

during the 3-min retrieval session in the reconsolidation group $(P=0.054)$. On both days 1 and 2 , there was no effect of postreversal drug treatment on freezing (all $P>0.05$ ). These results are consistent with those reported in experiment 2 ; the consolidation and reconsolidation groups were brought to similar levels of freezing prior to amnestic treatment and testing.

Figure 7B shows that when anisomycin was injected directly into the hippocampus, anisomycin-treated mice in both the consolidation and reconsolidation groups showed similar levels of freezing that were lower than vehicle-treated mice during the test $1 \mathrm{~d}$ following reversal. During the 1-d test, anisomycin-treated mice froze less than did vehicle-treated mice, as revealed by a significant main effect of drug $\left(F_{(1,30)}=14.8, P=0.001\right)$ and no reliable drug $\times$ context treatment interaction $\left(F_{(1,30)}=0.11, P=\right.$ $0.75)$. This effect was driven by less freezing in the anisomycintreated relative to the vehicle-treated mice in both the consolidation $\left(t_{(15)}=3.0, P=0.009\right)$ and reconsolidation groups $\left(t_{(15)}=2.5\right.$, $P=0.026)$, suggesting the presence of consolidation and reconsolidation deficits. The two anisomycin-treated groups did not differ $(P=0.19)$ during the first test.

The second test $14 \mathrm{~d}$ later (Fig. 7C) continued to reveal an anisomycin-induced consolidation deficit, but not a reconsolidation deficit. Statistical analysis of the 14 -d test revealed a reliable main effect of both context treatment $\left(F_{(1,30)}=12.2, P=0.002\right)$ and drug $\left(F_{(1,20)}=6.2, P=0.019\right)$, but no reliable drug $\times$ context treatment interaction $\left(F_{(1,30)}=1.4, P=0.25\right)$. There was less freezing in the anisomycin consolidation group relative to their vehicle $\left(t_{(15)}=3.6, P=0.002\right)$ and relative to the anisomycintreated reconsolidation mice $\left(t_{(15)}=2.6, P=0.019\right)$, but the reconsolidation drug groups showed no differences in freezing levels $(P=0.15)$. The intrahippocampal results therefore demonstrate that even when the magnitude of the initial deficit is matched, consolidation deficits persist longer than do reconsolidation deficits.

\section{Experiment 5b: Short nonreinforced exposure (intrahippocampal) with only 14-d test}

To investigate whether the initial 1-d test influences the recovery or persistence of memory deficits on the 14-d test, we tested a subset of animals only at the 14-d retention interval. As in experiment $5 \mathrm{a}$, the consolidation group continued to show a freezing deficit, whereas the reconsolidation deficit was not present (see Fig. 7D). During the 14-d test, there was a reliable main effect of drug group $\left(F_{(1,29)}=7, P=0.011\right)$ and no reliable context treatment $\times$ drug group interaction $\left(F_{(1,29)}=3.4, P=0.08\right)$. Further analyses confirmed that anisomycin-treated mice in the consolidation group froze less than did their vehicle controls $\left(t_{(13)}=2.6, P=\right.$
0.02), but there was no reliable simple effect of drug within the reconsolidation group $(P=0.46)$.

\section{Summary of major findings}

Studies of recovery sometimes examine the change in performance from one test (e.g., $1 \mathrm{~d}$ ) to a later test (e.g., $14 \mathrm{~d}$ ), but this change in behavior across time is not an ideal comparison because performance fluctuates and the first test itself will influence performance on the second (e.g., Kamin 1957; Estes 1997). Instead, a more direct and appropriate comparison for spontaneous recovery is to examine differences between two groups at a common test point (see Rescorla 1988, 2004, for further discussions). As such, Figure 8 summarizes the findings from these experiments as a difference score between mean freezing levels in vehicle- and anisomycin-treated mice during the 1-d and 14-d tests. While the statistical analyses of these data are discussed above, visualizing the data in this way facilitates general comparisons of the size and persistence of memory deficits, as well as the influence of repeated testing on the persistence of such memory deficits. In experiments 1 and 2, the size of the consolidation deficit was larger compared to the reconsolidation deficit during the 1-d test, but in experiment 3 the size of this deficit was matched. What is striking from Figure 8 is that the consolidation impairment (defined as the difference between the means of anisomycin- and vehicle-treated groups) is flat across tests; there was no evidence that this deficit decreased with time. However, in both experiments 2 and 3, the reconsolidation deficit got smaller during the 14-d test, even when the initial deficit was statistically identical in magnitude to the consolidation deficit. This recovery effect in the reconsolidation group was particularly pronounced when the 14-d test was not confounded by the 1 -d test (Fig. 8, open bars).

\section{Discussion}

The main finding from these experiments is that when overall experience and levels of performance prior to injections were matched, anisomycin-induced consolidation deficits were larger and more persistent than were reconsolidation deficits. All mice received the same amount of reinforced and nonreinforced context exposure with anisomycin injections delivered immediately after the second exposure. This treatment also resulted in vehicletreated mice in both consolidation and reconsolidation groups showing identical levels of freezing during the test sessions, which makes direct comparisons more meaningful between anisomycintreated groups. This comparison revealed larger behavioral deficits in freezing when systemic anisomycin followed a reinforced

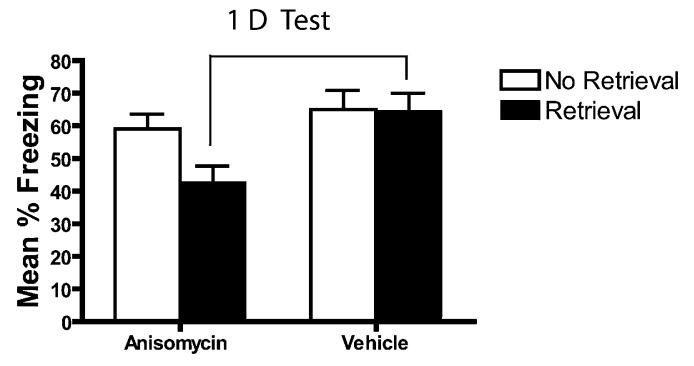

Figure 5. Anisomycin treatment has no effect when it does not follow a memory retrieval trial. One day after contextual fear conditioning mice either received a 3-min re-exposure to the conditioning CTX (retrieval) or were moved to the experimental procedure room and handled (no retrieval). Mice were then injected with either anisomycin or vehicle immediately and $2 \mathrm{~h}$ later. When tested $1 \mathrm{~d}$ later, mice treated with anisomycin following memory retrieval had a significant impairment, while those that did not experience a retrieval trial showed no such deficit. 
A

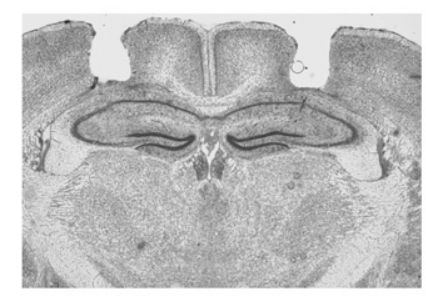

B

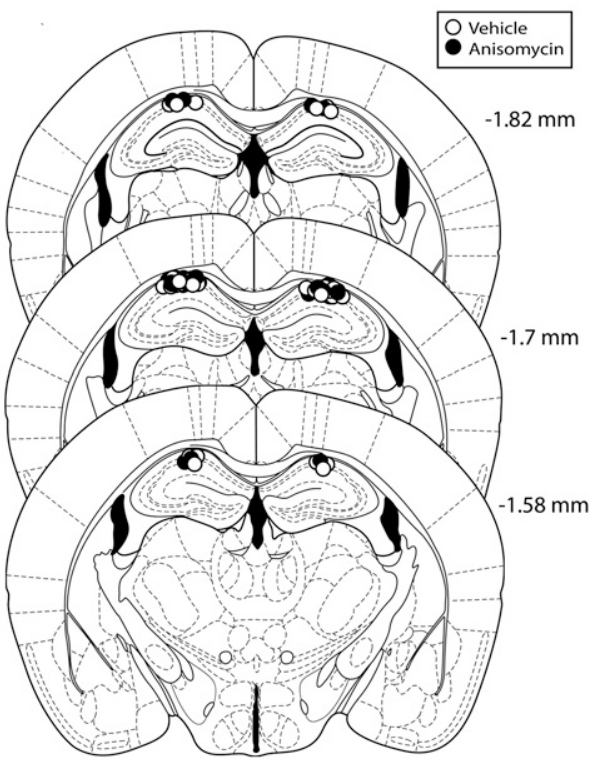

Figure 6. Hippocampal cannula placements. $(A)$ Photomicrograph depicting a representative sample of an accurate bilateral dorsal hippocampal injector placement. The coronal slice was stained with cresyl violet and was taken from $-1.7 \mathrm{~mm}$ bregma. (B) Actual injector tip placements in each animal used in experiment 5.

session (consolidation) compared to when it followed a nonreinforced session (reconsolidation). The size of the deficits was matched statistically with intrahippocampal injections, but only the consolidation deficit persisted during a retention test.

There is now a large amount of literature examining consolidation and reconsolidation processes (reviewed in Alberini et al. 2006; Amaral et al. 2008; Nader and Hardt 2009). However, most of what is known about these processes comes from separate experiments and inferences about the differences between these processes are often drawn from post-hoc comparisons between groups that were examined at different times, under different conditions, and often in different laboratories. These comparisons are useful for determining general themes that emerge from the literature, but they are not ideal for making specific conclusions about subtle differences between learning processes because many known and unknown variables may influence behavior (e.g., Rescorla and Holland 1976; Rescorla 1988; Estes 1997; Crabbe et al. 1999). A much more direct approach is to examine different memory processes in common assessments that match history and conditions for performance. This approach has been used in several recent experiments examining the amount and persistence of learning during initial acquisition and extinction (e.g., Rescorla 2002, 2005; McNally and Westbrook 2006; Bradfield and McNally 2008; Leung and Westbrook 2008). Although our procedures are slightly differ-

A.

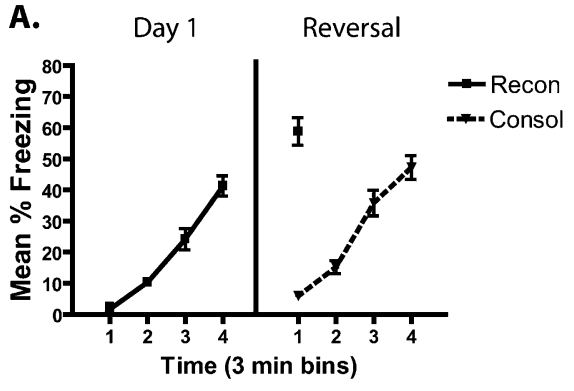

C.

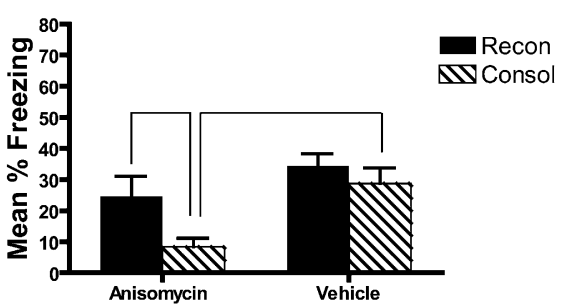

ent, the logic of our approach is the same: match the overall history of the organisms as closely as possible and assess their learning against a common testing baseline. This allows for a much more direct comparison of consolidation and reconsolidation processes because differences in levels of performance and overall experiences are less likely to influence the organism's ability to express the memory on test day (cf. Estes 1997; Biedenkapp and Rudy 2004, 2007). It is important to note, however, that although our approach matches the overall experience that the organisms have with the context, as well as the level of freezing, prior to anisomycin injections, it does not match all factors that may influence subsequent performance. Evaluating these factors-such as timing of the injection relative to shock and the quality of the experience during reinforced and nonreinforced exposures-will be important for future studies, especially those using a within-subjects approach to consider.

Our findings show that when these experiences and initial levels of performance are matched, consolidation deficits are more persistent than are reconsolidation deficits. This is consistent with many studies, although other studies have shown persistent reconsolidation deficits (reviewed in Amaral et al. 2008). There are a number of experimental factors that may influence the

西




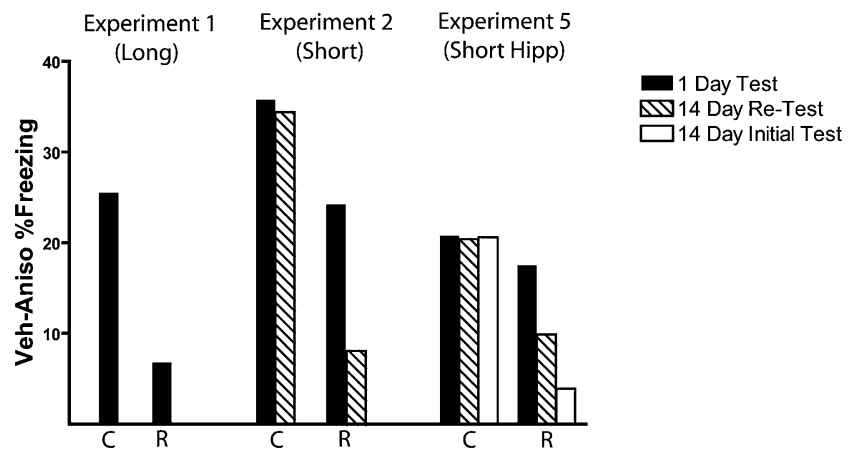

Figure 8. Summary of major experimental findings with memory deficits on test days expressed as the difference between vehicle and anisomycin treated animals within reconsolidation (R) and consolidation (C) groups. In experiment 1 a robust consolidation deficit was seen, whereas no reconsolidation deficit was observed. When the memory retrieval and pre-exposure sessions were shortened to $3 \mathrm{~min}$, a reliable consolidation and reconsolidation deficit was produced by systemic anisomycin treatment (experiment $2)$. The consolidation deficit was initially larger than the reconsolidation deficit (1-d test) and persisted to $14 \mathrm{~d}$, while the reconsolidation deficit did not (14-d test). Following intrahippocampal injections in experiment 5 , the sizes of the reconsolidation and consolidation deficits were matched statistically (1-d test). Only the consolidation deficit persisted to the 14-d test. Removing the confound of repeated testing yielded an even less persistent reconsolidation deficit (open bars). In experiments 2 and 5, the consolidation deficit remains flat from the first to the second tests, whereas the reconsolidation deficit decreases in size across tests.

persistence of any effect on memory. One long-appreciated factor is the test-retest problem; the first memory test soon after learning is itself a learning experience that will influence performance on subsequent tests (Rescorla 1988; Estes 1997). In an extensive review, Estes (1997) argues that the use of repeated testing in studies of memory has severely limited the conclusions that can be made about memory processes because of the clear effects that initial tests have on subsequent tests. This is especially true in studies with animals that use extinction testing; during the first test, the animal learns that the previously conditioned stimulus is no longer associated with the unconditioned stimulus. If animals express a memory deficit during this test, they will freeze less compared to their control group, which may result in a greater association between the cues on that test with extinction and the absence of conditioned responding (Estes 1955, 1997). Thus, when testing occurs again sometime later, any recovery from the initial behavioral deficit may be masked by the new extinction learning that occurred during that first test.

Many studies examining consolidation and reconsolidation issues use repeated testing, often including short-term, long-term $(24 \mathrm{~h})$, and longer-term $(3+\mathrm{d})$ tests in the same subjects. Thus, by the time the longer-term test occurs, animals have had multiple extinction sessions that are likely to impact the performance on the final test and make any behavioral deficit appear more persistent than it may actually be in the absence of repeated extinction testing. Although studies of memory consolidation have demonstrated that repeated testing may not contribute to the persistence of the memory deficit (e.g., Luttges and McGaugh 1967), many studies have demonstrated that spontaneous recovery after extinction is weakened by repeated testing (e.g., Pavlov 1927). Our findings are consistent with this, as Figure 8 shows consolidation deficits were unaffected by repeated testing, but reconsolidation deficits appeared more persistent when repeated testing was used (see also Lattal and Abel 2004; JM Stafford and KM Lattal, in prep). It is therefore particularly important that assessments of persistent reconsolidation deficits are not confounded by earlier testing.
One reason that has been offered for the differences in persistence between consolidation and reconsolidation deficits is that these deficits may differ in initial size (e.g., Duvarci and Nader 2004). If reconsolidation deficits are smaller compared to consolidation deficits (e.g., Figs. 2 and 3), the size of the deficit may contribute to the persistence, particularly when repeated testing is used. As can be seen in Figure 8, which summarizes the results of our experiments, there was no evidence for recovery in the consolidation groups in any experiment-performance in anisomycin-treated groups relative to vehicle-treated groups did not change from the 1-d test to the 14-d test. In the reconsolidation groups, however, the difference between anisomycin and vehicle groups decreased from the 1 -d test to the 14-d test, even when the 1-d difference was statistically identical to that of the consolidation group (experiment 5). This recovery effect was more pronounced when the 14-d test was not confounded by the 1-d test. Together, these findings demonstrate that a major factor influencing whether behavior recovered with time was whether the initial impairment followed the formation of context-shock memories or the retrieval of those memories, independent of the size of the deficit.

These findings by themselves do not provide direct theoretical evidence for why memory consolidation or reconsolidation deficits might differ in size or persistence. A great deal of attention has been given to whether memory consolidation and reconsolidation deficits reflect differences in memory storage or memory expression (reviewed in Amaral et al. 2008; Nader and Hardt 2009). As noted in these reviews and elsewhere, these all-or-none accounts make for good theories, in that they make explicit predictions about whether behavioral deficits should reverse with time, but they also likely fail to capture the complexities in the system. Further, the many documented differences between effects following initial learning and retrieval suggest that the label "reconsolidation," which implies a very specific theoretical process, may not accurately characterize the nature of the plasticity that follows these different experiences (e.g., Biedenkapp and Rudy 2004; McGaugh 2004; Miller and Matzel 2006; Amaral et al. 2008).

Our results and reconsolidation-like results in general, are also consistent with other ways of talking about performance that do not appeal to reconsolidation processes. Although the label reconsolidation has become synonymous with "post-test performance impairment," it is a theoretical term that describes only one of a number of theoretical possibilities. For example, many modern theories of reconsolidation-like effects are variants of stimulus sampling theory (see e.g., Riccio et al. 2006; Amaral et al. 2008), which contains memory storage and memory retrieval mechanisms that can account for differential effects of spontaneous recovery (e.g., Estes 1955; Bower 1994). Theories based in the logic of stimulus sampling need only assume that the components of a stimulus representation that are active during an amnestic treatment will be most vulnerable to the effects of that treatment. After an initial learning experience, a large proportion of the stimulus representation will be active, whereas after retrieval of a learning experience, only a portion of that representation will be active (see Riccio et al. 2006). Thus, post-retrieval manipulations should affect a smaller component of the stimulus, and, as time passes, sampling of the intact stimulus representation should increase. This reasoning was used by Estes to account for extinction, spontaneous recovery, and memory erasure (e.g., Estes 1955).

Any time a manipulation is administered after a nonreinforced retrieval trial, actions on extinction processes must also be considered. Extinction and reconsolidation are often pitted against each other as distinct processes at the molecular, neural systems, and behavioral level (Duvarci and Nader 2004; Riccio et al. 2006; Mamiya et al. 2009). Although extinction is often 
described as new memory formation, many theories of extinction have long appealed to depressions and other modifications to some aspect of the original memory without appealing to reconsolidation mechanisms (reviewed in Delamater 2004; Lattal et al. 2006; Lattal 2007b; Myers and Davis 2007). Thus, an alteration in aspects of the original memory is a perfectly plausible mechanism for extinction to be enhanced. Further, the absence of spontaneous recovery, renewal, and reinstatement have often been used as evidence that extinction processes are not facilitated in studies of reconsolidation, but it is certainly true that any manipulation that should enhance extinction should also weaken spontaneous recovery and associated phenomena (see Davis et al. 2006). Studies of reconsolidation-like processes in humans are consistent with these extinction accounts, because behavior in these experiments is often eliminated without affecting the subjects' knowledge of the original contingencies (e.g., Norrholm et al. 2006, 2008; Kindt et al. 2009). Indeed, this distinction between observed behavior and knowledge of the original association forms the cornerstone of modern thinking about extinction in animals (Rescorla 2001).

Clearly, there are different theoretical interpretations for results like ours. The important points are that multiple processes need to be considered when analyzing differences in recovery and that learning processes can be effectively enhanced through depressions in different memory systems. This is especially true with drugs, such as anisomycin, that have a variety of biological effects not limited to protein synthesis inhibition (e.g., Canal et al. 2007). The value in the experience matching approach used here is that it allows for direct comparisons to be made between different memory processes at behavioral and molecular levels that are not confounded by overall experience with the stimulus or levels of performance before or after the memory deficit. Several recent experiments have demonstrated important cellular and molecular differences between post-acquisition and post-retrieval processes (Lee et al. 2004; von Hertzen and Giese 2005; Parsons et al. 2006). Applying this behavioral experience matching approach to both molecular and theoretical investigations would therefore facilitate direct comparisons between the molecular and behavioral consequences of these memory processes.

\section{Acknowledgments}

This work was supported by National Institutes of Health grants R01MH077111 to K.M.L. and AG023477 to J.M.S. We thank Rick Bernardi and Chris Cunningham for helpful comments and discussions.

\section{References}

Alberini CM. 2008. The role of protein synthesis during the labile phases of memory: Revisiting the skepticism. Neurobiol Learn Mem 89: 234-246. Alberini CM, Milekic MH, Tronel S. 2006. Mechanisms of memory stabilization and de-stabilization. Cell Mol Life Sci 63: 999-1008.

Amaral OB, Osan R, Roesler R, Tort AB. 2008. A synaptic reinforcementbased model for transient amnesia following disruptions of memory consolidation and reconsolidation. Hippocampus 18: 584-601.

Biedenkapp JC, Rudy JW. 2004. Context memories and reactivation: Constraints on the reconsolidation hypothesis. Behav Neurosci 118: 956-964.

Biedenkapp JC, Rudy JW. 2007. Context pre-exposure prevents forgetting of a contextual fear memory: Implication for regional changes in brain activation patterns associated with recent and remote memory tests. Learn Mem 14: 200-203.

Boatman JA, Kim JJ. 2006. A thalamo-cortico-amygdala pathway mediates auditory fear conditioning in the intact brain. Eur J Neurosci 24: 894-900.

Bower GH. 1994. A turning point in mathematical learning theory. Psychol Rev 101: 290-300.

Bradfield L, McNally GP. 2008. Unblocking in Pavlovian fear conditioning. J Exp Psychol Anim Behav Process 34: 256-265.

Canal CE, Chang Q, Gold PE. 2007. Amnesia produced by altered release of neurotransmitters after intra-amygdala injections of a protein synthesis inhibitor. Proc Natl Acad Sci 104: 12500-12505.
Crabbe JC, Wahlsten D, Dudek BC. 1999. Genetics of mouse behavior: Interactions with laboratory environment. Science 284: 1670-1672.

Davis M, Ressler K, Rothbaum BO, Richardson R. 2006. Effects of Dcycloserine on extinction: Translation from preclinical to clinical work. Biol Psychiatry 60: 369-375.

Delamater AR. 2004. Experimental extinction in Pavlovian conditioning: Behavioural and neuroscience perspectives. Q J Exp Psychol B 57: 97132.

Duvarci S, Nader K. 2004. Characterization of fear memory reconsolidation. I Neurosci 24: 9269-9275.

Estes WK. 1955. Statistical theory of spontaneous recovery and regression. Psychol Rev 62: 145-154.

Estes WK. 1997. Processes of memory loss, recovery, and distortion. Psychol Rev 104: 148-169.

Hinderliter CF, Webster T, Riccio DC. 1975. Amnesia induced by hypothermia as a function of treatment-test interval and recooling in rats. Anim Learn Behav 3: 257-263.

Huang HJ, Liang KC, Chen CP, Chen CM, Hsieh-Li HM. 2007. Intrahippocampal administration of $A \beta_{1-40}$ impairs spatial learning and memory in hyperglycemic mice. Neurobiol Learn Mem 87: 483-494.

Kamin LJ. 1957. The retention of an incompletely learned avoidance response. J Comp Physiol Psychol 50: 457-460.

Kindt M, Soeter M, Vervliet B. 2009. Beyond extinction: Erasing human fear responses and preventing the return of fear. Nat Neurosci 12: 256-258.

Lattal KM. 2007a. Effects of ethanol on the encoding, consolidation, and expression of extinction following contextual fear conditioning. Behav Neurosci 121: 1280-1292.

Lattal KM. 2007b. Extinction and the erasure of memories. Psychol Science Agenda 21: 3-4; 16-18.

Lattal KM, Abel T. 2004. Behavioral impairments caused by injections of the protein synthesis inhibitor anisomycin after contextual retrieval reverse with time. Proc Natl Acad Sci 101: 4667-4672.

Lattal KM, Radulovic J, Lukowiak K. 2006. Extinction: Does it or doesn't it? The requirement of altered gene activity and new protein synthesis. Biol Psychiatry 60: 344-351.

Lattal KM, Barrett RM, Wood MA. 2007. Systemic or intrahippocampal delivery of histone deacetylase inhibitors facilitates fear extinction. Behav Neurosci 121: 1125-1131.

Lee JL. 2008. Memory reconsolidation mediates the strengthening of memories by additional learning. Nat Neurosci 11: 1264-1266.

Lee JL, Everitt BJ, Thomas KL. 2004. Independent cellular processes for hippocampal memory consolidation and reconsolidation. Science 304 839-843.

Leung HT, Westbrook RF. 2008. Spontaneous recovery of extinguished fear responses deepens their extinction: A role for error-correction mechanisms. J Exp Psychol Anim Behav Process 34: 461-474.

Luttges MW, McGaugh JL. 1967. Permanence of retrograde amnesia produced by electroconvulsive shock. Science 156: 408-410.

Mamiya N, Fukushima H, Suzuki A, Matsuyama Z, Homma S, Frankland PW, Kida S. 2009. Brain region-specific gene expression activation required for reconsolidation and extinction of contextual fear memory. I Neurosci 29: 402-413.

McGaugh JL. 2004. Memory reconsolidation hypothesis revived but restrained: Theoretical comment on Biedenkapp and Rudy (2004). Behav Neurosci 118: 1140-1142.

McGaugh JL, Roozendaal B. 2009. Drug enhancement of memory consolidation: Historical perspective and neurobiological implications. Psychopharmacology 202: 3-14.

McNally GP, Westbrook RF. 2006. Predicting danger: The nature, consequences, and neural mechanisms of predictive fear learning. Learn Mem 13: 245-253.

Miller RR, Matzel LD. 2006. Retrieval failure versus memory loss in experimental amnesia: Definitions and processes. Learn Mem 13: 491-497.

Myers KM, Davis M. 2007. Mechanisms of fear extinction. Mol Psychiatry 12: $120-150$.

Nader K, Hardt O. 2009. A single standard for memory: The case for reconsolidation. Nat Rev Neurosci 10: 224-234.

Norrholm SD, Jovanovic T, Vervliet B, Myers KM, Davis M, Rothbaum BO Duncan EJ. 2006. Conditioned fear extinction and reinstatement in a human fear-potentiated startle paradigm. Learn Mem 13: 681-685.

Norrholm SD, Vervliet B, Jovanovic T, Boshoven W, Myers KM, Davis M, Rothbaum B. 2008. Timing of extinction relative to acquisition: A parametric analysis of fear extinction in humans. Behav Neurosci 122: 1016-1030.

Parsons RG, Gafford GM, Baruch DE, Riedner BA, Helmstetter FJ. 2006. Long-term stability of fear memory depends on the synthesis of protein but not mRNA in the amygdala. Eur I Neurosci 23: 1853-1859.

Pavlov IP. 1927. Conditioned reflexes, an investigation of the physiological activity of the cerebral cortex. Oxford University Press, London, UK.

Rescorla RA. 1988. Behavioral studies of Pavlovian conditioning. Annu Rev Neurosci 11: 329-352. 
Rescorla RA. 2001. Experimental extinction. Handbook of contemporary learning theories (eds. RR Mowrer and S Klein), pp. 119-154. Erlbaum, Mahwah, NJ.

Rescorla RA. 2002. Comparison of the rates of associative change during acquisition and extinction. J Exp Psychol Anim Behav Process 28: 406-415.

Rescorla RA. 2004. Spontaneous recovery. Learn Mem 11: 501-509.

Rescorla RA. 2005. Spontaneous recovery of excitation but not inhibition. $J$ Exp Psychol Anim Behav Process 31: 277-288.

Rescorla RA, Holland PC. 1976. Some behavioral approaches to the study of learning. Neural mechanisms of learning and memory (eds. MR Rosenzweig and EL Bennett), pp. 165-192. MIT Press, Cambridge, MA.
Riccio DC, Millin PM, Bogart AR. 2006. Reconsolidation: A brief history, a retrieval view, and some recent issues. Learn Mem 13: 536-544.

Vecsey CG, Hawk JD, Lattal KM, Stein JM, Fabian SA, Attner MA, Cabrera SM, McDonough CB, Brindle PK, Abel T, et al. 2007. Histone deacetylase inhibitors enhance memory and synaptic plasticity via CREB:CBPdependent transcriptional activation. J Neurosci 27: 6128-6140.

von Hertzen LS, Giese KP. 2005. Memory reconsolidation engages only a subset of immediate-early genes induced during consolidation. $J$ Neurosci 25: 1935-1942.

Received April 13, 2009; accepted in revised form May 25, 2009. 


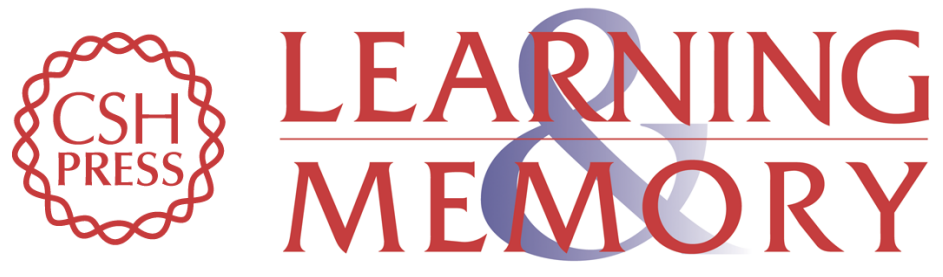

\section{Direct comparisons of the size and persistence of anisomycin-induced consolidation and reconsolidation deficits}

James M. Stafford and K. Matthew Lattal

Learn. Mem. 2009, 16:

Access the most recent version at doi:10.1101//m.1452209

References This article cites 45 articles, 15 of which can be accessed free at: http://learnmem.cshlp.org/content/16/8/494.full.html\#ref-list-1

License

Email Alerting Receive free email alerts when new articles cite this article - sign up in the box at the Service top right corner of the article or click here. 